\title{
Study to Assess the Health Profile of HIV Positive Orphans Living in Orphanages in India
}

\author{
Pranjal P Bobade ${ }^{1}$, Samir S Singru², Kevin Fernandez ${ }^{3}$
}

\begin{abstract}
Background and objectives: In the developing countries, the problem of human immunodeficiency virus (HIV) infection is serious. The burden of this disease in the developing countries cannot be estimated only from the disease morbidity and mortality. Children orphaned by human immunodeficiency virus/acquired immunodeficiency virus (AIDS) are one of the most fearful but yet unnoticed problem in our Indian community. This study aims to assess the health profile of HIV positive orphans in relation to physical health of HIV orphans. The objectives of the study were to assess the physical health profile of HIV positive orphans with respect to nutritional status and presence of opportunistic infections in HIV positive orphans of selected orphanages.

Materials and methods: Design of the study was cross-sectional. The study was carried out from September 2013 to March 2015 . With convenient sampling, two orphanages exclusively for HIV positive orphans were selected. The total number of orphans from both the orphanages was 84. The universal sampling method was used and all the HIV positive orphans were included in the study. Physical health of the HIV positive orphans was assessed by medical examination conducted by the investigator, anthropometry, and additional information procured from medical records of the orphans. Presence of any opportunistic infection was assessed by opportunistic infection checklist.

Results and conclusion: In the present study, it was observed that 22 orphan children (26\%) were underweight. It was observed that the total number of orphan children having opportunistic infection was 21 (25\%) and the most common opportunistic infection was pulmonary tuberculosis (TB) (8, 38\%).
\end{abstract}

Keywords: Human immunodeficiency virus, Nutrition, Opportunistic infections, Orphans.

SBV Journal of Basic, Clinical and Applied Health Science (2019): 10.5005/jp-journals-10082-02207

\section{INTRODUCTION}

Children are the ones who are vital for deciding how the world is going to be after some years. So if one can do some good in the life of a child then there can be a change, at least a slightest change, in the world to come. Children are gift by God; unfortunately not all children are brought up by their parents. Most of these orphans are placed in orphanages. According to UNAIDS, an orphan is a child below 18 years who has lost either one or both parents through death. A maternal orphan is a child who has lost his/her mother through death while a paternal orphan is a child who has lost his/her father as a result of death. A double orphan is a child whose both parents have died. ${ }^{1}$

Since the start of the epidemic, around 78 million [71-87 million] people have become infected with HIV and 39 million [35-43 million] people have died of AIDS-related illnesses. In 2013, there were 35 million [33.2-37.2 million] people living with HIV. New HIV infections have fallen by $38 \%$ since 2001 . New HIV infections among children have declined by $58 \%$ since 2001 . Worldwide, 240,000 $[210,000-280,000]$ children became newly infected with HIV in 2013, down from 580,000 [530,000-640,000] in 2001. In 2013, there were 4.8 million [4.1-5.5 million] people living with HIV in Asia and the Pacific. There were 22,000 [18,000-32,000] new HIV infections among children in Asia and the Pacific in 2013. Since 2009, there has been a $15 \%$ decline in new HIV infections among children in the region. ${ }^{2}$

HIV prevalence amongst children ( $<15$ years) in India has remained stable from 2007 to 2011 . It is $0.04 \%$ (0.03-0.05\%) during the years 2007 to 2011. The current round of estimates of number of people living with HIV is highest in Andhra Pradesh at around 4.20 lakh followed by that in Maharashtra at 3.15 lakh in 2011. Out of this 3.15 lakh in Maharashtra, 9.38\% were children less than 15 years of age. ${ }^{3}$

In developing countries, the number of individuals infected with HIV is on the increase. In India, as elsewhere, AIDS is often seen
${ }^{1}$ Station Health Organization, Ramgarh, Jharkhand, India

${ }^{2}$ Department of Preventive and Social Medicine, Smt. Kashibai Navale Medical College and General Hospital, Pune, Maharashtra, India

${ }^{3}$ Department of Community Medicine, AIMST University, Bedong, Kedah, Malaysia

Corresponding Author: Pranjal P Bobade, Station Health Organization, Ramgarh, Jharkhand, India, Phone: +91 9422128652, e-mail: pranjal.6009@gmail.com

How to cite this article: Bobade PP, Singru SS, Fernandez K. Study to Assess the Health Profile of HIV Positive Orphans Living in Orphanages in India. J Basic Clin Appl Health Sci 2019;2(2):73-75.

Source of support: Nil

Conflict of interest: None

as "someone else's problem"-as something that affects people living on the margins of society, whose lifestyles are considered immoral.

People living with HIV have faced violent attacks; been rejected by families and society; been refused medical treatment. Along with this the number of children infected and affected by HIV/AIDS is also on the rise. The problems of these children are different from that of adults in terms of physical, mental and social health. ${ }^{4}$

Children orphaned by HIV/AIDS are one of the most fearful but yet unnoticed problems in our Indian community. The stigma and discrimination which is related to this dreadful disease makes the life of the children more difficult. Although the Indian society is now improving but still the stigma and discrimination related to this disease is very dangerous. The minds and hearts of this HIV orphaned children is unable to tolerate this poison of stigma and 
discrimination which is faced by them in the age in which they should be playing and getting education from school as the normal healthy children.

The primary purpose of the current study is to add to the body of knowledge on the youth orphaned by AIDS' phenomenon and to give recommendations based on the study findings.

\section{Materials and Methods}

The design of the study was "Cross-sectional". The present study was carried out from September 2013 to March 2015. Two orphanages exclusively for HIV positive orphans were selected. The total number of orphans from both the orphanages was 84 . The universal sampling method was used and all the HIV positive orphans were included in the study. The age group was from 4 to 18 years.

The inclusion criteria was orphans infected with HIV/AIDS who gave consent for the study and the exclusion criteria was orphans who did not give consent for the study.

\section{Study Tools}

- Physical health of the HIV positive orphans was assessed by

- Medical examination conducted by the investigator.

- Anthropometry which included weight and height was included in the physical health sheet

- Additional information procured from medical records of the orphans

- Nutritional status of the child was assessed by BMI for age growth charts for boys and girls. $\geq 95$ th percentile was considered as overweight; 85 th to $<95$ th percentile was considered as risk of overweight and $<5$ th percentile was considered as underweight.

- Presence of any opportunistic infection was assessed by opportunistic infection checklist.

\section{Statistical Analysis}

The various variables related to physical, mental and social health were reported as percentages and Chi square test was used as a test of significance. $p$ value of 0.05 and less was considered as statistically significant. 95\% confidence interval was also calculated. Epi info software version 7 was used for statistical analysis.

\section{Results}

The age of children in the present study ranged from 4 to 18 years. Majority of the children were in the age group 10-14 years, i.e., $50 \%$ followed by $39 \%$ in the age group $15-19$ years, $7 \%$ in the age group 5-9 years, and least in the age group 0-4 years, i.e., 3.5\%. The percentage of females was more, i.e., $53.57 \%$ as compared to males $46.42 \%$ in the present study. The ratio of male to female children was 1:1.15.

It was observed that 22 orphan children $(26 \%, \mathrm{Cl}=16.4-35.6)$ were underweight with $\mathrm{BMI}$ for age percentile less than $5 \%$. Most of the orphan children, 62 (74\%) were of normal weight with BMI for age percentiles of in the range of $5-95 \%$ (Table 1).

The total number of orphan children with CD4 count less than 500 were $23(27 \%, \mathrm{Cl}=17.32-36.68)$, of which male children were 11 (28\%) and female children 12 (27\%). The total number of children with CD4 count of $>500$ were 61 (73\%).

The total number of orphan children having opportunistic infection were 21 ( $25 \%, \mathrm{Cl}=15.56-34.44)$, of which male children were 11 (28\%) and female children 10 (22\%). Out of the opportunistic infections the most common opportunistic infection was pulmonary TB $(8,38 \%)$ followed by oral candidiasis $(6,29 \%)$ followed by chronic persistent diarrhea $(3,14 \%)$ followed by followed by otitis media and recurrent fever with common cold ( $9.5 \%$ each).

The association of gender and nutritional status among orphan children in the present study was not found to be statistically significant. Amongst the orphan children, male orphans having CD4 cell count $<500$ were $11(28 \%)$ and female orphans having CD4 cell count $<500$ were $12(27 \%)$. The association of gender and CD4 count among HIV positive orphans in the present study was not found to be statistically significant. Amongst the HIV positive orphans, $11(28 \%)$ male orphans and 10 (22\%) female orphans were having opportunistic infections. The association of gender and presence of opportunistic infection among HIV positive orphans in the present study was not found to be statistically significant Table 2 .

Amongst the HIV positive orphans, 11 (50\%) undernourished and 12 (19\%) well-nourished HIV positive orphans were having CD4 cell count $<500 / \mathrm{mm}^{3}$. The association of under nutrition and low CD4 cell count among HIV positive orphans in the present study was found to be statistically significant.

Amongst the HIV positive orphans, 4 (18\%) undernourished and 17 (27\%) well-nourished HIV positive orphans were having presence of some opportunistic infection. The association of under nutrition and presence of opportunistic infection among HIV positive orphans in the present study was not found to be statistically significant.

Table 3 shows that amongst the orphan children with CD4 count $<500$, the opportunistic infection was present in 10 orphan

Table 1: Presence of opportunistic infection in study population

\begin{tabular}{ll}
\hline Males & Females \\
\hline $\begin{array}{l}\text { Pulmonary TB }=4(10.25 \%) \\
\text { Chronic persistent } \\
\text { diarrhea }=2(5.12 \%)\end{array}$ & $\begin{array}{l}\text { Pulmonary TB }=4(8.88 \%) \\
\text { Oral candidiasis }=4(8.88 \%)\end{array}$ \\
Oral candidiasis $=2(5.12 \%)$ & $\begin{array}{l}\text { Chronic persistent } \\
\text { diarrhea }=1(2.22 \%)\end{array}$ \\
$\begin{array}{l}\text { Recurrent fever with common } \\
\text { cold }=2(5.12 \%)\end{array}$ & Otitis media $=1(2.22 \%)$ \\
Total $=11(28 \%)$ & Total $=10(22 \%)$ \\
\hline
\end{tabular}

Table 2: Association of nutritional status and low CD4 cell count

\begin{tabular}{llll}
\hline & \multicolumn{2}{c}{ CD4 cell count in $/ \mathrm{mm}^{3}$} & \\
\cline { 2 - 3 } Nutritional status & $<500$ & $>500$ & Total \\
\hline Undernourished & $11(50 \%)$ & $11(50 \%)$ & $22(100 \%)$ \\
Normal & $12(19 \%)$ & $50(81 \%)$ & $62(100 \%)$ \\
Total & $23(27 \%)$ & $61(73 \%)$ & $84(100 \%)$ \\
\hline
\end{tabular}

$x^{2}$ value $=6.206, p=0.013, \mathrm{OR}=4.167$, dof $=1,95 \% \mathrm{Cl}=1.463-11.867$

Table 3: Association of CD4 count and presence of opportunistic infection

\begin{tabular}{llll}
\hline \multirow{2}{*}{$\begin{array}{l}\text { CD4 count in } \\
\text { cells } / \mathrm{mm}^{3}\end{array}$} & \multicolumn{2}{l}{ Presence of opportunistic infection } & \\
\cline { 2 - 3 } & Present & Absent & Total \\
\hline$<500$ & $10(43 \%)$ & $13(57 \%)$ & $23(100 \%)$ \\
$>500$ & $11(18 \%)$ & $50(82 \%)$ & $61(100 \%)$ \\
Total & $21(25 \%)$ & $63(75 \%)$ & $84(100 \%)$ \\
\hline
\end{tabular}

$x^{2}$ value $=4.490, p=0.034, \mathrm{OR}=3.497, \mathrm{dof}=1,95 \% \mathrm{Cl}=1.222-10.007$ 
children (43\%). The association of low CD4 count and presence opportunistic infection in the present study was found to be statistically significant.

\section{Discussion}

Majority of children were in the age group 10-14 years, i.e., 50\% followed by $39 \%$ in the age group $15-19$ years, $7 \%$ in the age group 5-9 years, and least in the age group $0-4$ years, i.e., $3.5 \%$. The percentage of females was more, i.e., $53.57 \%$ as compared to males $46.42 \%$ in the present study. The ratio of male-to-female children was 1:1.15.

Our study findings were comparable to study findings of Thakor et al. who did a cross sectional study in the year 2011 in NGO of Ahmedabad city amongst 90 HIV positive children in the age group of 5-14 years which consisted of 53\% females and $47 \%$ males (male:female ratio $=1: 1.12$ ) ${ }^{5}$ In a longitudinal study done by Mahesh et al. in antiretroviral therapy (ART) centre of Karnataka Institute of Medical Sciences (KIMS) Hubli, Karnataka during 2010 to 2011 among 82 HIV orphans which consisted of 53 (64.7\%) males and 29 (35.3\%) females in the age group 4-18 years (male:female ratio $=1: 1.82){ }^{6}$ Swetha et al. did an observational study in July 2009 to 2011, which included 77 HIV positive children in two orphanages in Hyderabad, India, aged between 1.5 years and 15 years. There were $48 \%$ males and $52 \%$ females (male:female ratio $=1: 1.08)^{7}{ }^{7}$ In the present study, it was observed that 22 orphan children (26\%) were underweight with BMI for age percentile less than $5 \%$. Most of orphan children, 62 (74\%) were of normal weight with BMI for age percentiles of in the range of 5-95\%. The prevalence of underweight was observed more in males (28\%) as compared to females (24\%). Our study findings were in accordance to the findings of Thakor et al. in the year 2015 , found that amongst 90 HIV positive children, the overall prevalence of malnutrition was $20 \%$, being high $(20.8 \%)$ in the male children than in the female children (19\%). ${ }^{5}$ Swetha et al. in the year 2015 observed that out of 77 orphans, $15(19.5 \%)$ had low BMI for age. In terms of BMI for age, boys (29.7\%, 11/37) appeared to be more undernouished when compared to girls $(10 \%, 4 / 40){ }^{7}$ Berger did a study in 2007 in Nyanja province of Kenya among 170 HIV positive children and found that the prevalence of under nutrition amongst the study population was $32 \% .^{8}$ in the present study, the total numbers of orphan children having opportunistic infection were 21 (25\%), of which male children were 11 (28\%) and female children 10 (22\%). Out of the opportunistic infections the most common opportunistic infection was pulmonary TB $(8,38 \%)$ followed by oral candidiasis $(6,29 \%)$ followed by chronic persistent diarrhea $(3,14 \%)$ followed by followed by otitis media and recurrent fever with common cold ( $9.5 \%$ each). Our study findings were comparable to findings of a study done by Gomber et al. in 2011, it was found that among 59 children, Tuberculosis was the most common opportunistic infection diagnosed in $11 \%$ of children. ${ }^{9}$ Swetha et al. in an observational study in 2015 found that out of 77 , pulmonary tuberculosis was the most common opportunistic infection seen in $13(16.8 \%)$ children. ${ }^{7}$

\section{LIMITATION}

The study has small sample size, further studies with a larger sample size needs to be undertaken for the better estimation of the prevalence of malnutrition, opportunistic infections of the HIV positive orphans.

\section{Results and Conclusion}

In the present study, total 84 HIV positive orphans in the age group ranging 4-18 years were studied. It was observed that 22 orphan children (26\%) were underweight with BMI for age percentile less than $5 \%$. Most of orphan children, 62 (74\%) were of normal weight with BMI for age percentiles of in the range of $5-95 \%$. While assessing the presence of opportunistic infection amongst the HIV positive orphans, it was observed that the total number of orphan children having opportunistic infection was 21 (25\%), of which male children were $11(28 \%)$ and female children 10 (22\%). The most common opportunistic infection was pulmonary TB $(8,38 \%)$ followed by oral candidiasis $(6,29 \%)$ followed by chronic persistent diarrhea $(3,14 \%)$ followed by otitis media and recurrent fever with common cold ( $9.5 \%$ each).

\section{Recommendations}

Based on our study findings following recommendations are made:

- Caregivers in the orphanages are one of the important personnel for ensuring the health of HIV positive orphans in their custody and they should undergo training in early identification of opportunistic infections according to the latest guidelines.

- For the improvement of the nutritional status of the HIV positive orphan children in an institutional care, training of the caregivers for the preparation of cost effective meals rich in protein and fat content is recommended.

- Since our sample size was small, further studies with a larger sample size needs to be undertaken for the better estimation of the prevalence of malnutrition, opportunistic infections in HIV positive orphans.

\section{References}

1. UNAIDS. 2008 Report on the Global AIDS Epidemic.

2. UNAIDS Global stats FACT SHEET 2013.

3. National AIDS Control Organization. Technical Report: India HIV Estimates National Institute of Medical Statistics, ICMR. New Delhi: NACO, DAC, Ministry of Health \& Family Welfare.

4. AIDS, Public Policy and Child Well-being. UNICEF 2000.

5. Thakor N, Gadhavi RN, Damor P, Baranda U, Bhagora S, Patel N. Sociodemographic profile and health status of children living with HIV-AIDS attached to an NGO (ADHAR) of Ahmedabad city. Int J Med Sci Public Health 2015;4(6):773-776. DOI: 10.5455/ ijmsph.2015.02012015156.

6. Mahesh V, Bant DD, Bathija GV. Clinical and psychosocial profile of HIV orphans in Northern Karnataka-a longitudinal study. Glob J Med Public Health 2013;2(3):1-6.

7. Swetha GK, Hemalatha R, Prasad UV, Murali V, Damayanti K, Bhaskar V. Health \& nutritional status of HIV infected children in Hyderabad, India. Indian J Med Res 2015;14(1):46-54. DOI: 10.4103/ 0971-5916.154494.

8. Berger MR. Prevalence of malnutrition in HIV/AIDS orphans in the Nyanza Province of Kenya. J Am Diet Assoc 2008 Jun;108(6): 1014-1017. DOI: 10.1016/j.jada.2008.03.008.

9. Gomber S, Kaushik JS, Chandra J, Anand R. Profile of HIV Infected Children from Delhi and Their Response to Antiretroviral Treatment. Indian Pediatr 2011;48:703-707. DOI: 10.1007/s13312-011-0117-7. 